\title{
Analysis of the Influence of New Media on People's Values — Take Youth Sports as an Example
}

\author{
${ }^{1}$ Shanghai Jianping High School, Shanghai, 200135, China \\ a1554694828@qq.com
}

Xuefei Zhong,a

\begin{abstract}
Both exercise and new media are an essential part of human daily life, and this paper will examine the effect of new media on people's willingness to exercise, using young people as an example. This paper analyzes the effects of both external and internal factors by comparing the research proposal of the government's measures used to increase the frequency and time of people's physical activity ---- to invest in the construction of fitness equipment and the continuous development of new media on young people's willingness to exercise. It finds out that although more government funding in gyms may be a good solution, it does not address the root cause of people's motivation to exercise. Fortunately, the emergence of new media is overcoming this problem and is gradually influencing young people's ideas and enthusiasm for exercise. Therefore, the study suggests that new media is a more worthwhile investment than gyms to improve young people's physical health.
\end{abstract}

Keywords: new media, young people, health, sports, solution

Keywords: new media, young people, health, sports, solution

\section{INTRODUCTION}

In November 2015, China's State General Administration of Sports released the "2014 National Physical Fitness Monitoring Bulletin." The overweight rate of adults in 2014 was $32.7 \%$, which has risen 0.6 percentage points from 2010; the obesity rate of adults was $10.5 \%$, which has risen 0.6 percentage points from 2010" [1]. The external reason for the decrease in exercise may be due to the lack of exercise equipment. However, the opinions of the General Office of the State Council on Strengthening the Construction of National Fitness Venues for the Development of Mass Sports state that the government has taken relatively strong measures to support the national sports industry and plan the effective development of sports facilities. This has not brought significant help to increase the enthusiasm of young people for fitness, but people's enthusiasm for sports is reflected from another medium, such as the street dance trend brought by new media. This paper investigates the impact of new media as a platform for people's sports communication, where people can share sports, liking or praising one another together with other interactive ways. This is aimed at increasing young people's enthusiasm for sports. Such feedback will greatly increase their enthusiasm for sports and sharing sports and making reasonable adjustments. The study compares the impact brought by government investment in building stadiums with the impact of new media on young people's view of sports and finds that the new trend of national fitness brought by the development of new media will be the future of national sports. To deepen people's love and pursuit of sports, motivate people to exercise, raise the awareness of national fitness, make the concept of national fitness deeply rooted in people's hearts, and promote the development of the sports industry, new media needs more attention from us and investment from the government.

\section{OVERVIEW OF NEW MEDIA}

New media is an all-encompassing term used to refer to every kind of electronic communication imaginable as a result of innovations in computer technology. In contrast to "old" media (including newspapers, magazines, books, television, and other non-interactive media), new media consists of websites, online video/audio streaming, email, online social platforms, online communities, online forums, blogs, Internet telephony, online advertising, online education, etc. [14] In terms of movement, the development of new media has provided a space for people to communicate and share 
their personal experiences. People can analyze their exercise experience online or on an app, express their exercise stress, etc. In addition, new media has helped to present a variety of niche sports that correspond to the sports preferences of various people. For example, there are many popular videos on the "Bilibili" website, and many young women choose these exercise videos to exercise at home to lose weight. The development of new media has enriched the variety of sports and increased the enthusiasm of young people for sports.

\section{REASONS FOR PEOPLE'S LACK OF EXERCISE}

\subsection{People rely on transportation to get around}

The increasingly developed public transportation makes people rely more on tools for daily travel, which liberates their legs but also makes people neglect exercise. It is their urgent need to make the whole body move afterlife. According to the British Journal of education, society and Behavioral Science [2], exercise can reduce stress and promote the release of endorphins, and improve the immune system, beyond that, exercise affects psychological factors, such as confidence, it also reduces the risk of depression, and adjusts the threshold of discomfort or pain during and after exercise. However, people are not concerned about regular sports. World Health Organization found that $81 \%$ of people age between 11 and 17 were physically inactive in 2016 . Adult girls are less physical activity than boys, with 85 percent and 78 percent, respectively, failing to meet the recommendations for moderate to high-intensity physical activity of at least 60 minutes per day. As a result, people's physical fitness will become worse from one generation to the next.

\subsection{Simplification of sports forms}

The external reason for the decrease in exercise volume may be due to insufficient exercise equipment. The fitness center is an effective way to provide people with sports venues. Because young people are susceptible to external influences and have impulsive consumption characteristics, people are easily attracted to nearby fitness centers. This seems to indicate that if fitness centers become more and more widespread, people will prefer sports because it makes them easier to exercise. After exercise, they can also have more time to exercise, such as a break at noon after work. However, on the contrary, with the emergence of more and more fitness centers, after the emergence of impulsive consumption, many people will regret becoming gym members. This is because when applying for a card, they usually have a good imagination and people go through a period. After the movement of time, the fantasy will reach the figure, they want and stick to it. However, the lack of concentration seems to be that many young people feel "troubled" in real life [1]. Few people can insist on doing regular exercises, so many people having gym membership in the office have regretted it. Statistics from the study of Huazhong University of Science and Technology show that about $80 \%$ of people have regrets after handling card ideas. [4] For $80 \%$ of people, although they seem to be engaged in sports, such as obtaining a fitness card, they are not exercising because they have no subjective desire to exercise, and their motivation to exercise has not improved.

\section{THE IMPACT OF NEW MEDIA ON PEOPLE'S HEALTH HABITS}

\subsection{The impact of social media platforms on young people's health concepts}

Social media platforms have changed young people's stereotypical ideas about sports. In 2020, The Opinions of the General Office of the State Council on Strengthening the Construction of National Fitness Venues for the Development of Mass Sports" states that the government has taken relatively strong measures to support the national sports industry and plan the effective development of sports facilities. However, the concentration of fitness centers is not beneficial to the sports ideology of the masses. In addition, people's enthusiasm for sports should not be limited by the availability of sports venues. People may think that fitness sports need suitable venues and facilities, but the development of new media has solved this problem well by changing people's perceptions and turning them into suitable and convenient fitness venues, whether at home or outdoors. Every place can be a place for exercise as long as people are passionate enough about them. For example, since the launch of the series in 2004, Bamberger has taken nearly 22,000 photos showing various basketball courts, whether they are basketballs made with rolling hoops on the side of the barn, redesigned logos, and wheel covers, still using mud, bricks, alleys or these scenes. These show that sports are not affected by the venue and people can use these places at their will. Due to the psychological characteristics of young people's susceptibility to external influences, the new media has greatly affected their living habits. American sociologist Connie Panzarino once proposed the concept of "me in the mirror". He argues that "human behavior is determined to a large extent by this knowledge, which is formed primarily through social interaction with others. The evaluations and attitudes of others toward oneself are a "mirror" that reflects oneself. Thus, a person's self is formed in contact with others" [9]. New media have created a platform for people to communicate about sports, where people can share their personal experiences, and comments or compliments on social platforms are a way to interact. Such feedback will greatly increase their enthusiasm for the sport, their willingness to share it, and their ability to make 
reasonable adjustments. Therefore, instead of investing in the construction of stadiums, you should focus on the internal impact of new media on the construction of stadiums.

\subsection{The influence of short videos platform on young people's sports choices}

By changing information processing processes, human life has been completely transformed by new information technologies and infinite connections have been created between different fields and between elements and actors of these activities. (Manuel Castell 2001 :117), according to the 45th CNNC China Internet Development Report, by March 2020, China's short video users have reached 77325 million, and the user utilization rate is $85.6 \%$. Therefore, in the internet environment, with the rapid dissemination of information and the complexity of content, network opinion leaders play an increasingly important role in the process of information dissemination, become an important intermediary for information from the media to the audience, and promote the development of information. These actions can attract potential audiences more effectively and deeply. For example, Kayla Itsines, an Australian personal trainer, has 13.1 million followers on Instagram and over 20 million on Facebook. More than 50 million women follow her and the company on social media channels.

Social media has spawned an online exercise approach like "a personal trainer in your pocket," such as the "Sweat" app that offers fitness tips, as well as advice on healthy eating. It became a popular app in the Apple App Store in the week it had launched and soon has become the most popular fitness app in the world, with more than 5,000 workouts across 26 workout programs, from high-intensity interval training and strength to yoga, barre and Pilates. The result is that social media has grown to meet the exercise needs of people around the world.[13]

\subsection{The influence of new forms of TV programs on people's sports ideas}

Since 2018, it has been called the "Year of Hip-Hop" by the hip-hop community due to the popularity of many hip-hop competition-based online shows. After that, online compilations based on youth hip-hop culture set off a national hip-hop boom. Besides, many competitive programs also appeared to young people, attracting them to participate and watch with prizes by setting various levels and integrating sports elements and novelties. The arrival of new media has opened up new ideas for sports. Young people are no longer limited to having to go to the gym. They have more options and combine their interests, thus increasing their enthusiasm for sports.

\section{DISCUSSION}

The use of sports in new media also helps to attract sports fans with the help of new media platforms. The most representative applications are "WeChat" and "Goudong". The new technological revolution has made people's lives smarter. The rise of official sports accounts and sports applications has changed the state of people's spare time, enriched the way people play sports, and increased the fun of sports." WeChat Sports" brings sports to society through new media, putting sports on WeChat and spreading it through sharing, competition and likes from WeChat's circle of friends. The interaction between WeChat friends keeps creating "WeChat Sports" topics. The "Gudong Sports" application is a way to expand the place of interaction of real-life groups interested in sports to the Internet, bringing them together and expanding the social circle of these sports enthusiasts. It is a sports record dedicated to sports enthusiasts. Although their development time is very short, their influence is huge.

For society, the real meaning of "information" is not what is disseminated by the media in each era, but the social changes brought about by the media." Internet interest groups are groups of different Internet users who use the Internet as a platform and various similar interests as a bond to interact frequently on the Internet and form online interactive relationships" [10], and Canadian communication scholar McLuhan, in his "Understanding Media. Human expansion" mentions that "media is information in the social sense" [8]. In other words, people can communicate in a way that is appropriate to a certain medium only when that medium is available. For society, the real sense of "information" is not what is disseminated by the media in each era, but the social changes brought about by the media. It is this trend that drives the concept of sports and health, and it is the social changes brought about by media technology. In short, the development of new media for national fitness will be the new trend of national sports in the future. It deepens people's love and pursuit of sports, stimulates people's motivation to exercise, raises the awareness of national fitness, makes the concept of national fitness deeply rooted in people's hearts, and promotes the development of the sports industry.

However, sociologist Lazarsfeld once said in his book "The People's Choice" that mass media is a powerful tool that can be used for both good and evil. In general, it is more likely to be evil if it is not properly controlled. [12]. Therefore, people should make reasonable use of the advantages of new media, grasp the communication law of new media for comprehensive fitness with a positive attitude and innovative spirit, improve the ability of new media application, and make good use and management of new media. The media enhances the relevance and effectiveness of public opinion guidance. 
Therefore, it is not enough to invest in the construction of stadiums. We should solve this problem from the will. Due to economic and social development, people's working style and life rhythm have changed a lot from before. Leisure time is characterized by fragmentation, and people's demand for interactive expression and information is growing. The emergence of new media caters to people. The new demand. The indepth development of the Internet has enabled new media to penetrate all areas of people's lives. In the interactive development of media, a chain is finally formed. [11] Therefore, we should promote the flourishing development of sports and improve people's lives by investing in new media. Passion for sports. Conclusion

\section{CONCLUSION}

In conclusion, exercise is necessary to maintain the health of the human body so that the organs in the body can receive sufficient oxygen and nutrients to promote the growth and development of young people, health and exercise are inseparable. Technological advances have created a decrease in the necessary physical activities in people's lives, such as transportation instead of walking, but this has also led to the consequences of people exercising less. To improve people's health, the government has chosen to invest in sports facilities. However, it has been proven that people's enthusiasm for sports has not been improved and national health problems still exist. Although the development of new media has both advantages and disadvantages for young people, the excessive attention of young people to the cell phone network has been a major factor in the development of new media. But these disadvantages can be limited by parental and the new media-driven national fitness boom is the perfect choice to increase the enthusiasm of young people to exercise today. Expansion of sports content in the new media field can make young people pay more attention to sports-related health content than some content the expansion of sports content in the new media field can make young people pay more attention to sports-related health content than some content on the Internet that is harmful and not beneficial to young people's growth. The future of the new media will probably lead the country to reach new heights of enthusiasm for sports and effectively improve national health problems.

\section{REFERENCES}

[1]. http://sports.people.com.cn/n/2015/1125/c3586227855794.html.2015-11-25/2016-10-08./People's Daily Online: Released by the General Administation of Sport of China [EB/OL].

[2].https://www.nbm.org/exhibition/hoops-Hoopsan exhibition that ran at the National Building Museum in Washington DC from March 9 through December 1, 2019.

[3]. Fan Fangxu. Group Identity among Interesting Groups - A Case Study of Reader Group of Dooku [D].

[4]. https://cdmd.cnki.com.cn/Article/CDMD-104871011110135.htm-Huazhong University of Science and Technology, 2010:5.

[5]. Http://www.cssn.cn/Xwcbx/xwcbx_cbx/201504/t201 50417_1591495.shtml-Cai Qi. Interesting relationship culture in network virtual community [J]. Journalism and Communication Research, 2014(9):5.

[6]. http://www.persee.fr/web/revues/home/prescript/arti cle/homso_0018-4306_1967_num_5_1_3099

Marshall McLuhan. Understanding Media - On the Extension of Man [M]. Translated by He Daokuan. Nanjing: Yilin Press, 2011:6.

[7].https://dl.acm.org/doi/book/10.5555/518096 [United States] Manuel Castel. The rise of the network society $[\mathrm{M}]$.

[8].Xia Zhujiu, Wang Zhihong and other translations. Beijing: Social Sciences Archives Press, 2001:117.

[9]. Guo Qingguang. Course of Communication[M]. Beijing: Renmin University Press, 2011:72.

[10].https://d.wanfangdata.com.cn/periodical/ChlQZXJp b2RpY2FsQ0hJTmV3UzIwMjEwOTA5Eg96Z3Fu eWoyMDA2MDcwMTYaCHZ2azQ1dWI3-Xie

Yujin.Internet Interest Groups and Youth Development[J].Chinese Youth Studies, 2006(7):60.

[11].http://qikan.cqvip.com/Qikan/Article/Detail?id=71 04583872-Network Marketing Communication Mode and Innovation Analysis in the New Media Era, Zhu Xiaolei DOI: 10.14013/j.cnki.scxdh.2021.07.019.

[12].http://www.cnki.com.cn/Article/CJFDTotalXWZX200809002.htm-Kong Deming. Ensure the correct guidance of public opinion and improve the ability of public opinion guidance[J]. News Front, 2008 (09).

[13].Fitness app founder Kayla Itsines sells Sweat for \$400 million - Startup Daily Fitness app founder Kayla Itsines sells Sweat for $\$ 400$ million-SIMON THOMSEN- JULY 15, 202.

[14].https://www.techopedia.com/definition/416/newmedia/ Dictionary/ Techopedia. 